\title{
Perspectivas do território e desenvolvimento local: estudo sobre a constituição do município de Naviraí, MS, como polo urbano regional
}

\author{
Territory perspectives and local development: study on the constitution of \\ Naviraí, MS, as a regional urban pole
}

Territorio y desarrollo local: investigación sobre la constitución del municipio de
Naviraí, MS, como polo urbano regional

\author{
Jaiane Aparecida Pereira ${ }^{1}$ \\ Gabrielle Corrêa Zacarias ${ }^{1}$ \\ Marco Antônio Costa da Silva ${ }^{1}$
}

Recebido em 1\%/04/2019; revisado e aprovado em 31/10/2019; aceito em 20/11/2019

DOI: http://dx.doi.org/10.20435/inter.v22i2.2478

\begin{abstract}
Resumo: O objetivo do presente trabalho foi compreender como ocorreu a constituição e o desenvolvimento do município de Naviraí como polo urbano regional, tendo como aporte teórico a discussão sobre desenvolvimento local e território. Especificamente, buscou-se identificar as ações e os atores relevantes para a constituição do município, descrever historicamente como ocorreu a constituição do município e sua condição de polo urbano regional, como também examinar os aspectos territoriais e sua contribuição ao desenvolvimento local e regional. Para tanto, foi realizada uma pesquisa qualitativa descritiva, por meio de dados secundários e entrevistas semiestruturadas com três moradoras da cidade que estão relacionadas à história do município. Os resultados evidenciam que diversos aspectos convergiram para a constituição do município como polo urbano regional, iniciando-se com a colonização, fomentada pelo governo federal, associada à existência de recursos naturais que eram abundantes, e, consequentemente, por meio do aproveitamento das potencialidades locais, como a vocação agrícola. Diante desse contexto, indica-se a utilização da análise E-P-C-N, proposta por Saquet (2009), para compreender a configuração de um território e como suporte para pensar o desenvolvimento local endógeno sustentado. Ademais, discute-se a necessidade de criar condições de desenvolvimento endógeno a partir da conjugação de esforços locais com apoio externo, como as diversas universidades instaladas no município, que podem, por meio de esforços conjuntos, instruir os atores no sentido de promover o desenvolvimento local.
\end{abstract}

Palavras-chave: território; desenvolvimento local; Naviraí.

Abstract: This paper aims to understand how occurred the constitution and development of Naviraí as a regional urban pole, having as a theoretical support the discussion about local development and territory. Specifically, we seek to identify relevant actions and actors for the constitution of the city, to describe historically how occurred the constitution of the city and its condition of regional urban pole, as well to examine the territorial aspects and their contribution to the local and regional development. Therefore, we made a descriptive qualitative research, using secondary data and semi-structured interviews with three residents related to the city's history. The results show that several aspects converged to the constitution of Navirai as a regional urban pole, beginning with colonization, fomented by the federal government, associated with the existence of abundant natural resources, and, consequently, through the use of local potentialities, as the agricultural vocation. In this context, we indicate the use of E-P-C-N analysis, proposed by Saquet (2009), to understand the configuration of a territory and as a basis for thinking about sustainable endogenous local development. We also discussed the need to create conditions of endogenous development from the combination of local efforts with external support, such as the various universities installed in Navirai, which can - through joint efforts - instruct the actors to promote local development.

Keywords: territory; local development; Naviraí.

Resumen: El objetivo de esta investigación fue comprender cómo ocurrió la constitución y el desarrollo del municipio de Naviraí como polo urbano regional, teniendo como contribución teórica la discusión acerca de desarrollo local y territorio. En concreto, se buscó identificar las acciones y los actores relevantes para la constitución del municipio, describir históricamente cómo ocurrió su constitución y su transformación en polo urbano regional, como también examinar los aspectos territoriales y su contribución para el desarrollo local y regional. Para eso, se realizó una investigación cualitativa descriptiva, por medio de datos secundarios

\footnotetext{
${ }^{1}$ Universidade Federal de Mato Grosso do Sul (UFMS), Naviraí, Mato Grosso do Sul, Brasil.
} 
y entrevistas semiestructuradas con tres moradoras de la ciudad que están relacionadas con la historia del municipio. Los resultados evidencian que diversos aspectos hubieran contribuido para la constitución del municipio como polo urbano regional, empezando con la colonización, alentada por el gobierno federal, sumada a la existencia de recursos naturales abundantes, y, consecuentemente, por el aprovechamiento de las potencialidades locales, como la vocación agrícola. En este contexto, se indica la utilización del análisis E-P-C-N, propuesta por Saquet (2009), para comprender la configuración de un territorio y como soporte para pensar el desarrollo local endógeno sostenido. Además, discutimos también la necesidad de crear condiciones de desarrollo endógeno a través de la conjugación de esfuerzos locales con el apoyo externo, como las diferentes universidades presentes en el municipio, que pueden, por medio de esfuerzos conjuntos, instruir a los actores en el sentido de promover el desarrollo local.

Palabras clave: territorio; desarrollo local; Naviraí.

\section{INTRODUÇÃO}

A necessidade de regionalização do desenvolvimento tem sido tema de discussões por parte de pesquisadores, poder público e demais atores da comunidade (CABUGUEIRA, 2000). Isto porque as formas de desenvolvimento com efeito cascata, sendo pensadas de cima para baixo e sem considerar as desigualdades e peculiaridades regionais, não têm apresentado resultados homogêneos (FERRO, 2003). Neste contexto, a concepção de desenvolvimento local endógeno, planejada e conduzida por atores locais, tem se constituído como uma estratégia importante para suportar o crescimento de cidades periféricas e pequenas (AMARAL FILHO, 1996; SPOSITO; JURADO DA SILVA, 2013; ZANON, 2014; 2018).

Para Ávila (2000), o desenvolvimento local consiste no desabrochamento de capacidades, competências e habilidades de agenciamento e gestão de uma comunidade, a qual tenha interesses comuns e esteja situada em determinado território, possuindo identidade social e histórica. Essa perspectiva enfatiza a necessidade da participação comunitária e da valorização das potencialidades territoriais para pensar o desenvolvimento local e regional.

Ao adicionar a importância da comunidade e do território para o desenvolvimento local, volta-se a uma perspectiva territorial do desenvolvimento. Conforme destacaram Moraes e Schneider (2010), na perspectiva territorial de desenvolvimento, o local, ao lado do global, passa a ser um espaço onde as potencialidades e os recursos são aproveitados, a partir de uma estratégia local dos atores sociais e em consonância com oportunidades externas. Vale ressaltar que, apesar da conotação econômica contida na noção de desenvolvimento, para efetivamente pensar o desenvolvimento local e regional, é necessário envolver também os aspectos humanos e sociais, que são indissociáveis (PEREIRA et al., 2017).

A partir dessa visão epistemológica, considera-se que, a fim de entender a configuração de determinado território, faz-se necessário conhecer seus atores e sua história, para, posteriormente, tratar do desenvolvimento local. De acordo com Saquet (2015), um território é produzido no espaço e no tempo, por meio do exercício de poder de determinados grupos sociais ou indivíduos. O autor argumenta a necessidade de considerar o movimento e a relação recíproca entre as dimensões sociais do território para compreender sua formação. Essas dimensões envolvem os aspectos econômicos, políticos, culturais e da natureza, sendo denominada análise E-P-C-N (SAQUET, 2009; 2015).

Alguns estudos vêm sendo desenvolvidos no sentido de entender a formação de territórios (VALE; SAQUET; SANTOS, 2005; EDUARDO; SAQUET, 2010; FARIAS, 2013; SANTOS; PEREIRA; PAULA, 2018; PEREIRA; PEREIRA, 2018; PEREIRA; CHAGAS; BÁNKUTI, 2019). De forma geral, esses estudos se debruçam sobre a importância da interação/ligação entre os atores e o território, envolvendo 
identidade, relações sociais, redes e processos constantes de territorialização e desterritorialização. Por conseguinte, acredita-se que compreender questões dessa natureza, envolvendo os atores e os processos territoriais, pode ser a base para pensar o desenvolvimento local, tendo em vista a forte conexão entre comunidade, potencialidades territoriais e desenvolvimento endógeno.

Não obstante aos avanços teóricos nos estudos do campo do desenvolvimento local e regional e da abordagem territorial, ainda é possível constatar lacunas teóricas importantes, sobretudo na compreensão sobre como polos regionais são constituídos, para além da visão econômica. Visando contribuir neste quesito, optou-se por estudar o município de Naviraí no estado de Mato Grosso do Sul, no qual faltam estudos sobre sua história (GONÇALVES, 2015). Naviraí tem 55 anos, tendo sido promulgada como município no ano de 1963 (MESSIAS, 2013; IBGE [Cidades], s.d.). O município tem alcançado destaque no cenário regional com um crescimento populacional acentuado e com Produto Interno Bruto (PIB) maior do que os outros municípios que compõem a Microrregião de Iguatemi, classificação do IBGE que compreende 16 municípios (PEREIRA et al., 2017; IBGE [Cidades], s.d.).

Assim, esta pesquisa oferece contribuições teóricas e empíricas considerando a importância em compreender a configuração de territórios e sua relação com o desenvolvimento local, bem como a relevância do município de Naviraí para a região Sul do estado de Mato Grosso do Sul. Além disso, segue-se a sugestão de Pereira et al. (2017) sobre a necessidade de compreender como se deu o desenvolvimento de Naviraí como município polo, visando reunir dados que auxiliem na proposição de um projeto de desenvolvimento local e regional sustentado neste território.

Para tanto, o objetivo geral do presente trabalho foi compreender como ocorreu a constituição e o desenvolvimento do município de Naviraí como polo urbano regional sob o enfoque territorial. De forma específica, buscou-se identificar as ações e os atores relevantes para a constituição do município de Naviraí; descrever historicamente como ocorreu a constituição do município e sua condição de polo urbano regional; e examinar os aspectos territoriais e sua contribuição ao desenvolvimento local e regional.

\section{DESENVOLVIMENTO LOCAL E ABORDAGEM TERRITORIAL}

O desenvolvimento foi entendido por muito tempo como atrelado ao processo de industrialização e ao avanço tecnológico, sendo sinônimo apenas de crescimento econômico. Contudo, Sachs (2004) reitera que o crescimento não é sinônimo de desenvolvimento, pois, para o desenvolvimento ser completo, é necessário ampliar o emprego, reduzir a pobreza e atenuar as desigualdades, o que não ocorre apenas com o crescimento econômico.

Atualmente, o desenvolvimento passou a incorporar outros aspectos, como os sociais, as condições de saúde, de educação, habitação, entre outros (PINTO, 2014). Araújo et al. (2017) consideram o desenvolvimento como um processo que pressupõe transformações tanto nas relações econômicas quanto nas relações sociais de comunidades. Por esse motivo, a peculiaridade do desenvolvimento local reside no aproveitamento das potencialidades locais físicas, naturais, estruturais e políticas, despertando uma nova dinâmica econômica e social (FERRO, 2003). O local refere-se à escala das inter-relações pessoais da vida cotidiana que constroem sua identidade sobre uma base territorial (MARTINS, 2002).

Diante dessa nova dinâmica, pondera-se que o desenvolvimento deve ser visto por meio de uma perspectiva integrativa, envolvendo todos os atores locais e regionais, com grande ênfase 
na participação da comunidade em função de suas potencialidades territoriais (PEREIRA et al., 2017). O desenvolvimento local, por sua vez, pode se configurar como uma alternativa para que as comunidades locais se tornem gestoras do seu próprio desenvolvimento, baseando-se no social, no econômico e no material, formado pelos recursos naturais e tecnológicos (ARAÚJO et al., 2017).

Existe um entendimento generalizado de que, para o desenvolvimento local, é necessário que a estratégia seja própria do território, para que possa alcançar uma dinâmica econômica, social e ambiental sustentável (MARTINS, 2002). Do mesmo modo, Ávila (2006) discute que não é lógico pensar em planos e estratégias para o desenvolvimento local que sejam articulados de modo uniforme para sociedades em âmbito nacional. O autor salienta que é preciso respeitar as riquezas potenciais da localidade. Isto porque os indivíduos influenciam diretamente nos rumos, meios e métodos de cada local (ÁVILA, 2006).

Diante disso, reitera-se que o desenvolvimento local está atrelado à comunidade local, na qual os indivíduos podem pensar formas de desabrochar as propriedades comuns (ÁVILA, 2006). Neste caso, segundo Pinto (2014), o Estado não deve ser o único responsável pelas políticas de desenvolvimento, pois a comunidade deve ser coparticipante dessa construção. "O desenvolvimento não se dá apenas através das políticas públicas e de programas implementados pelo governo, mas a partir do envolvimento de todos os segmentos sociais, permitindo um diálogo entre as escalas local, regional e nacional" (PINTO, 2014, p. 171).

Deve-se conferir então um caráter mais humano ao desenvolvimento local, no qual haja a participação ativa das pessoas da comunidade, para que elas não sejam apenas beneficiárias do desenvolvimento, mas sim protagonistas (MARTINS, 2002; ARAÚJO et al., 2017), conferindo participação e responsabilidade aos envolvidos (FERRO, 2003). Portanto, apesar da existência de diversos determinantes que contribuem para o desenvolvimento local, a participação da comunidade é o principal deles, pois, ao se envolver e gerenciar seus recursos, as pessoas podem se emancipar, garantir acesso aos recursos e à cidadania (PINTO, 2014). O desenvolvimento da comunidade precisa ser pautado na participação social como elemento central, pois se constitui de um processo de cooperação social, já que a população tem interesses e necessidades comuns pelo fato de ocupar o mesmo espaço (PINTO, 2014).

Embora a participação dos atores locais seja condição fundamental, Cabugueira (2000) reitera que são necessárias estruturas de apoio para efetivamente promover o desenvolvimento local, seja de instituições públicas, seja de instituições privadas. O autor defende que as iniciativas individuais ou de grupos locais necessitam da entrada de profissionais do desenvolvimento, que são pessoas capazes de apoiar as iniciativas nas questões técnicas e no plano das relações de comunicação interpessoal e interinstitucional. Logo, "a conjugação de esforços locais, com os apoios exteriores (públicos ou privados) e a participação dos agentes de desenvolvimento são condições essenciais do desenvolvimento endógeno" (CABUGUEIRA, 2000, p. 135).

Além desses fatores, Pinto (2014) argumenta que o capital social, que envolve o nível de confiança entre os indivíduos, de participação, os valores e as normas, impacta no desenvolvimento, porém está condicionado a aspectos políticos, sociais e culturais. A singularidade cultural e territorial proeminente auxilia na manifestação do desenvolvimento por meio de caminhos próprios e produtos específicos e exclusivos do território (MARTINS, 2002).

Perante essas questões, a partir da lógica do desenvolvimento local aqui defendida, que envolve os aspectos econômicos, sociais, políticos e culturais, percebe-se uma articulação com a 
abordagem do território proposta por Saquet (2009; 2015), baseada na análise E-P-C-N. O conceito de território é bastante complexo e com diferentes perspectivas. Saquet (2015) argumenta, a partir da concepção de Lefebvre, que o território é um espaço modificado pelo trabalho e revela relações de poder. Por esse motivo, o território é objetivado por relações sociais, de poder e de dominação que implicam numa territorialidade (SAQUET, 2015).

Para compreender o território, é fundamental diferenciar o território do espaço. Para Raffestin (1993), o território se forma a partir do espaço, pois o espaço é anterior ao território. A partir dessa compreensão, Raffestin cita a construção de malhas, nós e redes, as quais são delimitadas por campos de ação e poder, constituindo-se em uma materialidade (SAQUET, 2015).

Devido à intensa discussão sobre o conceito de território, Vale, Saquet e Santos (2005) fazem um resgate do conceito e das diferentes abordagens que estão sendo produzidas nas Ciências Sociais. Em primeiro lugar, os autores citam que, na geografia moderna, o território foi enunciado por Ratzel, que destacava a preocupação com a constituição do Estado.

Outro teórico, Robert Sack, enxergava o território como um "produto da organização social e [que] a territorialidade corresponde às ações de influência e controle em uma área do espaço, tanto de indivíduos como de suas atividades e relações, o que pode ocorrer em diferentes níveis escalares" (SAQUET, 2015, p. 83). Para Sack (1986), a territorialidade está relacionada a como as pessoas usam a terra, como se organizam no espaço e também dão significados ao lugar.

De outra forma, porém baseando-se na argumentação de Raffestin, Giuseppe Dematteis compreende o território como campo de domínio e de controle, sendo fundado nas formas de socialização em uma dada formação territorial, envolvendo a comunicação, a cooperação e a troca (SAQUET, 2015). Dematteis (2005) estuda como os territórios, em escalas distintas, participam dos processos de desenvolvimento e transformação da sociedade, da cultura e do ambiente. A territorialidade, por sua vez, "é um fenômeno social, que envolve indivíduos que fazem parte de grupos articulados entre si, mediados pelo território; mediações que mudam no tempo e no espaço" (DEMATTEIS, 2005, p. 23).

A partir dessa visão, Saquet (2005) discute que o espaço está contido no território e é condição para a reprodução territorial. O espaço pode então ser visto como resultado de relações históricas e escalares, nas quais há uma conjugação entre aspectos da economia, da política, da cultura e da natureza exterior ao homem (SAQUET, 2005).

Esses aspectos são abordados diferentemente pelos teóricos, que contemplam as relações entre as dimensões ora privilegiando aspectos políticos e econômicos, ora econômicos e culturais, ou, ainda, aspectos culturais e políticos (VALE; SAQUET; SANTOS, 2005). Entretanto, para Saquet (2009), é fundamental reconhecer e apreender esses processos de forma concomitante, para a compreensão da formação do território, a territorialização. Por esse motivo, o autor propõe a análise E-P-C-N, que engloba todas as dimensões: econômicas, políticas, culturais e naturais (SAQUET, 2009; 2015). Assinala-se que essas dimensões variam para cada lugar e momento ou período histórico (VALE; SAQUET; SANTOS, 2005).

A análise E-P-C-N foi utilizada por Pereira e Pereira (2018) para compreender a formação do polo moveleiro do município de Arapongas, PR, e a constituição do Arranjo Produtivo Local (APL) de móveis. Como resultados, os autores identificaram que o polo moveleiro não foi constituído de forma tão deliberada quanto se havia pensado, e que os fatores políticos e econômicos foram mais importantes na sua formação. Além disso, o APL foi criado como consequência do polo, para melhorar a competitividade das micro e pequenas empresas do setor, sendo o papel do 
governo municipal relevante no sentido de buscar estratégias para a formação do território e para o desenvolvimento local (PEREIRA; PEREIRA, 2018).

Pereira, Chagas e Bánkuti (2019) utilizaram também a análise E-P-C-N para compreender as ações e os atores que configuraram o município de Marialva, no estado do Paraná, como um território produtor de uva fina (PEREIRA; CHAGAS; BÁNKUTI, 2019). Ao examinar cada uma das dimensões, por meio do histórico do município, os autores revelaram que todos os aspectos foram bastante relevantes na sua configuração, estando todos eles relacionados. Neste estudo, Pereira, Chagas e Bánkuti (2019) frisam que o desenvolvimento local precisa estar vinculado ao território. E, por isso, deve ser alvo de discussão por parte dos agentes públicos e da sociedade civil, pois o envolvimento de todos propicia um maior desenvolvimento territorial.

Diante dessas discussões, constata-se a importância de considerar o território para pensar o desenvolvimento local. Sendo assim, propõe-se a articulação dessas abordagens para entender historicamente a constituição do município de Naviraí como polo urbano regional.

\section{PROCEDIMENTOS METODOLÓGICOS}

O presente trabalho constituiu-se como uma pesquisa de natureza qualitativa do tipo descritiva (MICHEL, 2009), com recorte transversal de perspectiva longitudinal (RICHARDSON, 2008), pois a coleta de dados buscou analisar dados históricos que foram importantes para a constituição do território de Naviraí.

É importante destacar que a pesquisa está estruturada a partir de uma visão epistemológica que compreende o desenvolvimento local alicerçado em uma perspectiva endógena. Para tanto, a argumentação teórico-metodológica utilizada no texto se ampara e se estrutura nos campos teóricos do tempo, espaço e território, buscando articular as dimensões da economia, política, cultura e natureza, propostas por Saquet (2009; 2015). Conforme destacou o autor, as relações e interações que ocorrem do ponto de vista dessas dimensões são diversas, complexas, heterogêneas e ocorrem em momentos específicos, sendo fundamentais para descrever e explicar um determinado território.

Considerando o método, a pesquisa constitui um estudo de caso sobre a constituição e o desenvolvimento do município de Naviraí como polo urbano regional. A coleta de dados ocorreu em duas fases. A primeira delas, a partir de dados secundários, incluindo um levantamento de arquivos diversos, que continham a história do município, como documentos, relatórios, leis e publicações em revistas. Foram também utilizados trechos de entrevistas realizadas com pioneiros e publicadas por Messias (2013), em livro que foi lançado como parte das comemorações dos 50 anos do município. Os entrevistados naquela ocasião foram: (1) João Martins Cardoso, primeiro prefeito; (2) Ítalo Cândido de Marco, filho de pioneiro; (3) Sakae Kamitani, que chegou a Naviraí em 1961 para plantar hortelã e algodão; (4) Ronald Almeida Cançado, médico pioneiro e prefeito; e (5) Antônio Pires de Souza, médico pioneiro. Esses trechos de entrevistas foram aqui denominados de D1 a D5, respectivamente.

A segunda fase da pesquisa ocorreu por meio da coleta de dados primários. Tal coleta foi operacionalizada pela realização de entrevistas semiestruturadas com três moradoras da cidade que estão relacionadas à história do município, denominadas aqui de E1, E2 e E3.

O roteiro de entrevista foi dividido em duas partes: a primeira buscou investigar características demográficas dos sujeitos e seu histórico no município; a segunda analisou a visão 
das entrevistadas sobre os aspectos econômicos, políticos, culturais e da natureza de Naviraí, culminando na opinião das entrevistadas sobre o futuro da cidade e sua condição de polo urbano regional. Nas duas etapas realizadas, buscou-se compreender as relações e interações construídas ao longo da história do município de Naviraí para as dimensões do E-P-C-N.

As entrevistas foram realizadas no mês de julho de 2018 e tiveram duração média de 30 minutos. O Quadro 1 apresenta um resumo dos dados sobre as entrevistadas.

Quadro 1 - Resumo dos dados sobre as entrevistadas

\begin{tabular}{|c|c|c|c|c|}
\hline Entrevistado & $\begin{array}{c}\text { Chegada a } \\
\text { Naviraí }\end{array}$ & De onde veio & $\begin{array}{c}\text { Local de } \\
\text { nascimento }\end{array}$ & $\begin{array}{c}\text { Relação com a história de } \\
\text { Naviraí }\end{array}$ \\
\hline E1 & 1953 & Pacaembu, SP & Correntes, PE & Filha de pioneiro e professora \\
\hline E2 & 1967 & $\begin{array}{c}\text { Santa Cruz de } \\
\text { Monte Castelo, PR }\end{array}$ & Lins, SP & $\begin{array}{c}\text { Esposa de pioneiro e } \\
\text { vereadora }\end{array}$ \\
\hline E3 & 2008 & Dourados, MS & Ronda Alta, RS & $\begin{array}{c}\text { Conhecimento da história } \\
\text { devido à profissão } \\
\text { (bibliotecária) }\end{array}$ \\
\hline
\end{tabular}

Fonte: Autores com base nos dados da pesquisa.

Observa-se que a primeira entrevistada se instalou na cidade em 1953, um ano após a chegada dos primeiros moradores, e foi professora. A segunda entrevistada foi esposa de um dos pioneiros, é vereadora e chegou à cidade após 15 anos do início, em 1967. A terceira entrevistada chegou mais recentemente, em 2008, e é bibliotecária. Acredita-se que a percepção das entrevistadas em épocas diferentes foi importante para compreender o desenvolvimento do município.

Por fim, todos os dados, primários e secundários, foram analisados a partir da técnica de análise de conteúdo (MINAYO, 1994; TRIVIÑOS, 2010). As categorias analisadas emergiram da literatura estudada, a saber: economia, política, cultura, natureza e desenvolvimento. É importante frisar que as entrevistas realizadas, bem como os dados secundários coletados, permitiram coletar um robusto conjunto de informações, que, a partir da utilização do E-P-C-N, permitiu capturar os processos que contribuíram para formação do território em análise.

Assim, a análise de dados nesta pesquisa foi construída no sentido de estabelecer uma abordagem histórica, de relações e interações do território e sua territorialidade capaz de reconhecer a unidade entre as dimensões que explicasse a constituição e o desenvolvimento do município de Naviraí. A escolha dessa abordagem contribui diretamente para o alcance do objetivo do artigo, sobretudo por tratar-se de uma perspectiva teórico-metodológica que permite compreender a apropriação do território de forma holística, na perspectiva do todo, da influência das dimensões E-P-C-N e da importância de cada uma delas para o todo.

\section{DISCUSSÃO E ANÁLISE DOS DADOS}

A análise dos dados foi dividida em duas partes. Inicialmente, apresenta-se um panorama histórico sobre a constituição do município, incluindo aspectos econômicos, sociais, culturais e da natureza (E-P-C-N). Ressalta-se que a análise não foi realizada de forma separada para cada aspecto discutido por Saquet (2009), dada a característica imbricada dos aspectos nos 
dados históricos levantados. Depois, foram descritas e analisadas a visão dos pioneiros sobre o desenvolvimento de Naviraí e sua condição de polo urbano regional.

\subsection{Panorama histórico sobre o município de Naviraí}

O município de Naviraí está localizado ao sul do estado de Mato Grosso do Sul, na microrregião de Iguatemi. Sua área é de $3.193,552$ km², que equivale a $14,47 \%$ da microrregião e 1,09\% do total do estado. A posição geográfica do município está limitada ao norte, pelo município de Jateí; ao sul, pelos municípios de Itaquiraí e Iguatemi; a leste, pelo estado do Paraná; e a oeste, pelo município de Juti (PREFEITURA MUNICIPAL DE NAVIRAí [PMN], s.d.; IBGE [Cidades], s.d.). O município está localizado na bacia hidrográfica do Rio Paraná e os principais rios são: Curupaí, Laranjaí, Amambai e Paraná (MESSIAS, 2013).

Ao analisar os Censos Demográficos do Instituto Brasileiro de Geografia e Estatística (IBGE), observa-se o aumento acentuado da população do município. A evolução da população residente foi de: 23.117 pessoas em 1970; 36.662 pessoas no ano de 2000; 46.424 pessoas em 2010; e estimativa de 53.188 em 2018 (IBGE [Cidades], s.d).

A densidade demográfica foi de 14,54 habitantes por $\mathrm{km}^{2}$ no ano de 2010 (IBGE [Sidra], 2011). A figura 1 mostra a localização do município de Naviraí no estado de Mato Grosso do Sul, bem como a densidade de demográfica em todo o estado. Observa-se que a densidade demográfica está no nível mais alto, o que mostra uma concentração de pessoas. Como o município é relativamente novo, essa concentração revela um potencial como polo urbano regional.

Para entender como ocorreu a constituição do território, é necessário contar e analisar sua história. A colonização da região de Naviraí começou no ano de $1952^{2}$, a partir da compra de duas glebas, Naviraí e Bonito, pela colonizadora Vera Cruz Mato Grosso Limitada (GONÇALVES, 2015). Nesta época, a região era habitada pelos índios Guarani e o acesso ao povoado era alcançado apenas por via fluvial, pelo rio Amambai (MESSIAS, 2013; GARCIA, 2016).

\footnotetext{
${ }^{2}$ Ressalta-se que a chegada da colonizadora foi motivada por uma política nacional, que vinha sendo desenvolvida desde a década de 1930 pelo governo federal, por meio do projeto conhecido como Marcha para Oeste. Para conhecer todo o contexto histórico da região, veja Gonçalves (2015).
} 
Figura 1 - Localização de Naviraí e densidade demográfica em relação ao estado

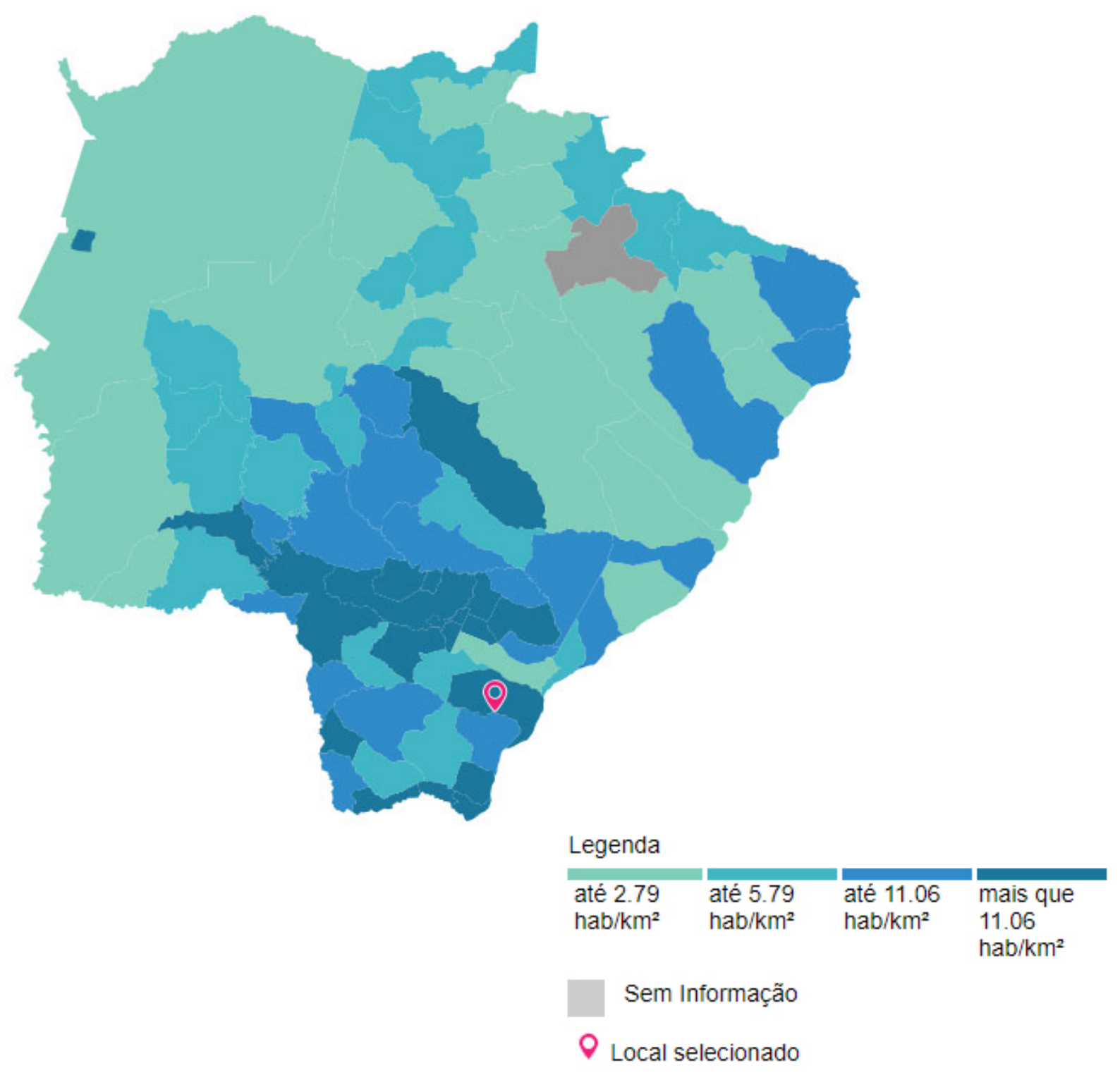

Fonte: IBGE (s.d.).

O grupo de empreendedores, notadamente Ariosto da Riva, vindos do município de Vera Cruz, no estado de São Paulo, juntam as duas glebas que deram origem à cidade de Naviraí (GONÇALVES, 2015). Seu cunhado, Antônio Augusto dos Santos, nascido em Minas Gerais, que inicialmente veio como trabalhador braçal (MESSIAS, 2013), foi quem buscou naquele estado um engenheiro para realizar o projeto urbanístico da cidade. Naviraí foi construída de forma planejada, em forma de teia, como mostrado na figura 2.

A forma de teia foi inspirada nos modelos urbanos de Belo Horizonte, em Minas Gerais, que, por sua vez, foi inspirada em Paris e Washington (GARCIA, 2016). No memorial descritivo da formação da cidade, foi citado que o modelo seguia os "moldes modernos do urbanismo da época" (GONÇALVES, 2015, p. 49). 
Figura 2 - Vista aérea da teia de Naviraí

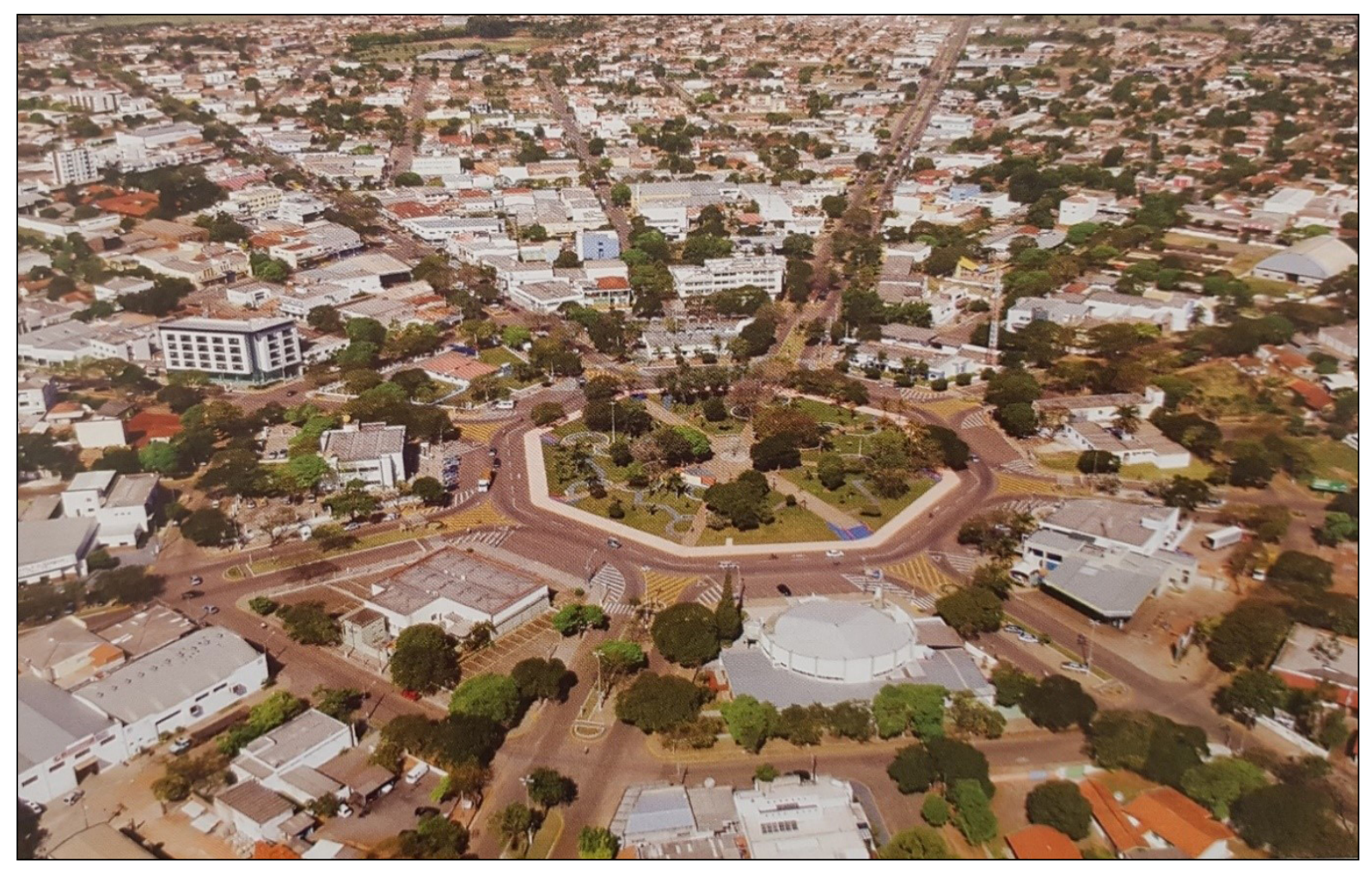

Fonte: Hasper e Pereira (2013, p. 132).

Oficialmente, a origem do nome Naviraí tem duas versões: (1) nome de um pequeno rio que os primeiros colonizadores encontraram ao chegar, Naviraí, de origem Guarani, significava "pequeno rio impregnado de arbustos roxos" ou "rio impregnado de pequenas árvores arroxeadas"; e (2) relacionado a Natividad, do castelhano, que significa nascimento (HASPER; PEREIRA, 2013; GARCIA, 2016; PMN, s.d.). Contudo, a entrevistada E2 revela que, segundo Antônio Augusto dos Santos, figura importante no desenvolvimento da cidade 3 , o "Navi" era de novidade, nascimento, e o "Inrai" era o nome de uma flor de cor roxa, o que culminou em Naviraí. De toda forma, Gonçalves (2015) discute que, embora tenha base indígena, não se pode afirmar com precisão o significado do nome, pois a versão oficial não tem fundamento etimológico e científico.

Os primeiros colonizadores começaram a explorar a madeira. Na vegetação original, destacava-se o cerrado e a mata tropical, com árvores como a peroba, o cedro, angico-vermelho e canafístula (PMN, s.d.). Em 1953, começaram a ser instaladas as primeiras serrarias. O município chegou a ter 79 serrarias (GONÇALVES, 2015). Observa-se que, inicialmente, os recursos naturais foram importantes para a colonização do território e para o desenvolvimento da economia do município, relacionando os aspectos natureza e economia (SAQUET, 2015).

Segundo Garcia (2016), a exploração da madeira ajudou a desenvolver o comércio local, porém, com o fim da extração, houve muito desemprego, o que parece ter contribuído a uma migração do trabalho para a atividade agrícola, que já vinha sendo exercida. Em 1954, com a

\footnotetext{
${ }^{3}$ Antônio Augusto dos Santos, conhecido popularmente como "Virote", embora tenha chegado em 1952 como trabalhador braçal, era homem de confiança de Ariosto da Riva, trabalhou cerca de 20 anos como funcionário da colonizadora e, depois, em 1972, tornou-se sócio e diretor da empresa. Desempenhou também várias funções no município como subdelegado de polícia, vereador e prefeito (GONÇALVES, 2015).
} 
chegada de novas famílias, notadamente de origem japonesa, iniciou-se o cultivo de café, algodão e erva-mate (GARCIA, 2016). Os migrantes começaram a chegar de várias regiões do Brasil, especialmente dos estados vizinhos, São Paulo e Paraná (GARCIA, 2016). Segundo Gonçalves (2015), a colonizadora contratava vendedores para divulgação da venda de lotes, sobretudo dos estados de Mato Grosso, Paraná, São Paulo e Minas Gerais.

Vale destacar que um dos vendedores de lotes da colonizadora Vera Cruz foi Moriyoshi Fukuda, primeiro migrante de origem japonesa a se mudar para Naviraí, tornando-se um intermediário para que outras famílias dessa origem se mudassem também para o local (GONÇALVES, 2015).

Em 1955, foi concluído o primeiro acesso rodoviário que ligava Naviraí ao município de Dourados, mesmo que de forma precária (MESSIAS, 2013; GARCIA, 2016). Em 1958, Naviraí foi elevada ao posto de distrito. E, em 11 de novembro de 1963, por meio da Lei Estadual n. 1944, foi promulgada a categoria de município, sendo Naviraí então desmembrada do município de Caarapó. Em 1977, com a separação dos estados, passou a fazer parte do atual estado de Mato Grosso do Sul (MESSIAS, 2013).

Para se tornar município, E2 reitera que foi importante o papel do então deputado estadual Weimar Gonçalves Torres, responsável pela documentação e tramitação para que Naviraí fosse politicamente independente. A articulação política dos dirigentes da colonizadora, principalmente de Ariosto da Riva, contribuiu para esse evento e para o desenvolvimento do município (GONÇALVES, 2015). A partir da municipalização, a atuação dos primeiros prefeitos, que foram pioneiros, foi também relevante para o seu desenvolvimento (E1; E2). Os primeiros prefeitos foram: João Martins Cardoso (1965 a 1967); Antônio Augusto dos Anjos (1967 a 1970); João Martins Cardoso (1970 a 1973); Antônio Augusto dos Anjos (1973 a 1977); Ronald de Almeida Cançado (1977 a 1983) (PMN, s.d.).

Entre os anos de 1960 e 1970, conforme Garcia (2016), o município de Naviraí tornou-se um atrativo para produtores e comerciantes que viam oportunidades de negócios, baseandose na grande quantidade de matérias-primas para venda. Para a autora, à medida que as madeireiras e serralherias foram perdendo espaço, as indústrias e o comércio foram ganhando foco. O município começou então a ganhar projeção em nível estadual e a criar sua identidade (MESSIAS, 2013). Em 1972, a cidade ocupava o oitavo lugar em arrecadação do imposto ICM de todo o estado (GONÇALVES, 2015).

Em seus anos de desenvolvimento, em termos gerais, o município passou por três fases econômicas: (1) extração da madeira e produção agrícola (principalmente plantio de café); (2) grande ciclo da madeira e a modernização da agricultura (ciclo do algodão) e criação de gado; e (3) desenvolvimento da agroindústria e prestação de serviços (GARCIA, 2016). Embora esses ciclos tenham envolvido processos de territorialização e desterritorialização (SAQUET, 2009), no caso estudado, observa-se que a vocação agrícola continuou com grande representatividade no desenvolvimento das atividades no município.

A agroindústria impulsionou o crescimento da cidade e da região, em especial a fundação da Cooperativa Agrícola Sul Matogrossense (COPASUL), em 1978, e da Cooperativa dos Produtores de Cana de Açúcar de Naviraí (COOPERNAVI), em 1980 (PMN, s.d). A COPASUL foi fundada por 27 cotonicultores, em sua maioria das famílias Kamitani e Suekane, liderados por Sakae Kamitani e Júlio Suekane (D3, COPASUL, s.d]). Além disso, a implantação de frigoríficos na década de 1980 trouxe também oportunidades de trabalho e fomentou a economia em Naviraí (E2). 
Constata-se que os aspectos culturais auxiliaram no desenvolvimento do município, principalmente a influência da cultura japonesa no cultivo da terra è na constituição da cooperativa. Além disso, a cultura do cooperativismo tem sido importante também para o crescimento do município.

A partir de então, o município vem se desenvolvendo, apesar de enfrentar alguns períodos de crise. Em 2006, a usina COOPERNAVI foi vendida para um grupo de americanos (OLIVEIRA, 2006). Depois, foi diminuindo o volume de trabalho até parar completamente, o que prejudicou a economia do município (E3). Ressalta-se que, em 2018, a usina voltou a funcionar. Quanto à indústria frigorífica, no presente momento, uma planta frigorífica de abate de bovinos e de couros está em posse do grupo JBS e opera normalmente.

Diante dessa trajetória, a Secretaria de Estado de Meio Ambiente e Desenvolvimento Econômico (SEMADE) do estado de Mato Grosso do Sul menciona que Naviraí tem força agropecuária e vem experimentando um rápido crescimento da indústria e agroindústria, com destaque para os setores de alimento (beneficiamento de carne, grãos, mandioca e leite), sucroalcooleiro, metalurgia, cerâmica e têxtil (SEMADE, 2015). Em 2018, o PIB per capita do município foi de $\mathrm{R} \$ 34.043,66$. A distribuição do PIB entre os setores, em 2018, destaca a importância do setor de serviços, com $36,10 \%$ do total, seguido por administração e serviços públicos, com 19,46\%; agropecuária, com 19,10\%; indústria, 15,25\%; e impostos, 10,09\% (IBGE, s.d.).

Quando se trata de trabalho e renda, o salário médio mensal dos trabalhadores formais em 2018 foi de 2,3 salários mínimos. Neste período, a população ocupada era de 11.505 pessoas, que corresponde a 21,3\% da população ocupada (IBGE [Cidades], s.d.). O Índice de Desenvolvimento Humano Municipal (IDHM), em 2010, era de 0,700, o que é considerado o limite mínimo do nível alto (PROGRAMA DAS NAÇÕES UNIDAS PARA O DESENVOLVIMENTO [PNUD], 2013).

Por conseguinte, Naviraí é vista como um polo econômico e de liderança urbana da Região do Cone-Sul, que abrange sete municípios no total, a saber: Naviraí, Juti, Itaquiraí, Iguatemi, Eldorado, Mundo Novo e Japorã (SEMADE, 2015). Ao analisar toda a Região do Cone-Sul, a SEMADE (2015) apresenta que a formação econômica é fundamentada na produção agropecuária, com destaque para a produção de grãos, como milho, soja e cana-de-açúcar, nos municípios de Naviraí e Itaquiraí. Além disso, a pecuária bovina de corte tem destaque, com maior expressão nos municípios de Iguatemi, Naviraí e Itaquiraí.

Sendo assim, pode-se discutir que todos os aspectos apontados por Saquet (2015) contribuíram para que Naviraí se constituísse como um polo urbano regional. Os aspectos da natureza, no papel dos recursos naturais que atraíram as pessoas para o local; os aspectos políticos, ao considerar os atores que influenciaram na criação e no desenvolvimento do município, notadamente os dirigentes da colonizadora e os pioneiros que foram prefeitos; os aspectos culturais, como os migrantes de diversas partes, sobretudo os japoneses, que influenciaram o cultivo na região e a difusão da cultura do cooperativismo; e os aspectos econômicos, com os ciclos de exploração da madeira, do algodão e da agroindústria.

Como se constata, a apropriação do espaço foi sendo construída ao longo dos anos em Naviraí, não apenas a partir da apropriação da terra que estava sendo explorada, em termos materiais, mas também por relações sociais que foram sendo constituídas do ponto de vista da ocupação do espaço e do poder, as quais permitem compreender e explicar como Naviraí foi construída, o que fornece atualmente pistas importantes sobre seu futuro. Constata-se que 
a "terra" de Naviraí se tornou território a partir de sua compreensão como meio e objeto de trabalho, de produção, de interação, de relações, trocas e cooperação, caracterizando a cidade como um ambiente socioespacial, onde o físico é um elemento muito bem integrado à estrutura social: economia, política e cultura (SAQUET, 2009; 2015).

\subsection{Visão dos pioneiros sobre o desenvolvimento de Naviraí}

Nesta seção da pesquisa, são descritos e analisados os dados referentes às entrevistas. Reforça-se a perspectiva adotada na pesquisa de utilização do E-P-C-N como estratégia para análise dos dados. Assim, é importante esclarecer que os aspectos econômicos, políticos, culturais e naturais serão apresentados de forma relacional, buscando as interações necessárias para compreensão da totalidade. Da mesma forma, buscou-se dos sujeitos entrevistados não apenas sua percepção histórica sobre a criação e o desenvolvimento do município, mas também o papel que desempenharam nessa construção, permitindo, assim, compreender melhor as relações e interações do território, de sua territorialidade e suas perspectivas futuras.

Em virtude da descrição da visão dos pioneiros, apresentam-se primeiramente os dados sobre as entrevistadas. Depois, discorre-se sobre a opinião das entrevistadas e dos pioneiros, cujas entrevistas constam em Messias (2013), sobre o desenvolvimento de Naviraí, incluindo as dificuldades enfrentadas e sua opinião sobre o futuro.

A primeira entrevistada (E1) mudou-se para Naviraí em 1953, aos 12 anos. Nasceu em Correntes, no estado de Pernambuco. Foi para Pacaembu, no estado de São Paulo, onde seu pai tinha um açougue, e depois foi de barco para Naviraí. Segundo a entrevistada E1, a família foi para Naviraí por causa do sogro da irmã, que foi o primeiro corretor da cidade e convidou toda a família.

Quando se trata das atividades desenvolvidas no município, a entrevistada E1 cita que trabalhou primeiramente na roça. Entre os anos de 1958 e 1961, foi professora. Depois, inaugurou a primeira agência dos Correios da cidade. Por motivos pessoais, foi morar em São Paulo por volta de 1972. Nessa época, foi vendedora de madeira que era extraída de Naviraí. Após 21 anos, retornou a Naviraí para ficar próxima da família.

Com relação aos familiares da entrevistada E1, vale ressaltar que eles foram importantes personagens na história do município. Seu cunhado, João Martins Cardoso, foi o primeiro prefeito de Naviraí, empossado em 1965. Sua irmã, ex-primeira-dama, foi homenageada com seu nome em uma escola do município. O pai, por ser um dos primeiros a chegar à cidade, foi também homenageado com o nome de uma rua.

A segunda entrevistada (E2) mudou-se para Naviraí em 1973, aos 20 anos, oriunda de Santa Cruz do Monte Castelo, no estado do Paraná. Nasceu em Lins, estado de São Paulo. Seu pai era descendente de alemães e nasceu em São José do Rio Preto, SP. Sua mãe era do estado de Minas Gerais.

A entrevistada foi para Naviraí se encontrar com o pai, que era gerente de serraria na época. Segundo ela, devido a uma chuva constante de mais de 20 dias, ficou presa na cidade e foi convidada a ser professora, pois já exercia essa profissão no Paraná. Somando-se a isso, E2 reitera que faltavam oportunidades de trabalho na sua cidade, e em Naviraí, pelo contrário, havia muitas oportunidades e faltavam profissionais, o que motivou sua permanência no local. Quando chegou à cidade, tinha uma amiga que estudou com ela no Paraná e que morava em Naviraí, ficando hospedada incialmente na casa dela. 
Desde então, a entrevistada E2 nunca se mudou e desenvolveu várias atividades no município. Atuou como professora até 1986; posteriormente, foi trabalhar na Associação de Pais e Amigos dos Excepcionais (APAE), desempenhando várias funções, como diretora, coordenadora, secretária, tesoureira. A partir desse trabalho, atuou em várias outras instituições, como clube de mães e lar do menor, o que contribuiu para que se tornasse vereadora, cargo que ocupou até 2020.

A terceira entrevistada (E3) mudou-se para Naviraí em 2008, para assumir um concurso público como bibliotecária. Morava no município de Dourados, MS, localizado a $140 \mathrm{~km}$. Nasceu em Ronda Alta, no estado do Rio Grande do Sul, e ela e seus pais, que eram agricultores, vieram a Dourados na década de 1970, para abrir lavoura em busca da melhoria financeira.

Sobre a mudança a Naviraí, o filho de pioneiro D2 conta que seu pai foi comprar um sítio para a família, em 1952. O entrevistado D2 foi em seguida, em 1954, com os demais membros da família, para plantar café. No momento da sua chegada, estava sendo extinta a extração da erva-mate nativa, a qual, de acordo com ele, era exportada por meio dos rios até chegar ao Mar del Plata, na Argentina. Depois disso, o café foi predominante até 1963, quando a madeira se tornou a maior fonte de renda (D2).

Pode-se notar que os recursos naturais atraíram os primeiros moradores, e a agricultura foi importante para o início do município. Com relação à agricultura, E1 revela que o café era abundante na região, porém as geadas frequentes desestimularam o plantio (E2). Aliado às geadas, outro problema enfrentado na época foi o escoamento da produção, como exemplificado por E2: "[...] porque aqui, como geava muito, o pessoal foi desanimando, mas deu muito café aqui em Naviraí, tanto café que eles até queimaram porque não tinha estrada para levar para fora, não tinha como vender".

Observa-se que a maior dificuldade enfrentada pelos pioneiros inicialmente foi o acesso, que era feito apenas de barco ou de avião (E1; E2). Como cita E2,

Havia a dificuldade de locomoção daqui para fora, era só avião; quem tinha condições para pagar um avião, de vez em quando pousava um, se pegava uma carona e pagava uma carona cara. Ou, então, você tinha que apelar para ônibus mesmo. Para quem tinha carro próprio, saía sem saber que horas chegaria, então era bastante difícil na época.

O difícil acesso ocasionava também a falta de mercadorias, de mão de obra e de médicos, como relata E1. A chegada dos primeiros médicos, em 1968, segundo D1, auxiliou na melhoria da qualidade de vida na cidade. Os médicos chegaram a Naviraí recém-formados, com expectativa de atender os mais necessitados, como reitera D4. Todavia, enfrentaram também muitas dificuldades, como a ausência de profissionais de enfermagem e a falta de estrutura, inclusive energia elétrica (D4; D5).

Para D1, a principal dificuldade nos seus mandatos como prefeito foi a falta de recursos financeiros para que a prefeitura pudesse atuar, o que culminava na necessidade de obtenção de ajuda por parte dos fazendeiros instalados no local, principalmente de Ariosto da Riva e Morioshi Fukuda. De modo semelhante, E1 reitera sobre as dificuldades enfrentadas pelos prefeitos: "Não tinha quase nada de imposto, [...] ia fazer com o quê? Não tinha quase nada, mesmo assim, [o primeiro prefeito] colocou placa nas ruas, comprou uma ambulância, já melhorou, né. Uma patrola para fazer estrada, abriu rua que aqui não tinha".

Com relação à atuação dos prefeitos, a entrevistada E1, que conheceu todos eles, destaca a gestão do prefeito Euclides Antônio Fabris, que assumiu em 1997. Segundo ela, a cidade 
mudou bastante durante essa gestão: "[...] o que eu percebi de prefeito que [...] assim que deu um sacode em Naviraí foi o seu Euclides, que [...] deixou Naviraí com aspecto de cidade" (E1).

Quando se trata do comércio, E1 destaca que, no começo, havia apenas um estabelecimento que vendia tudo, de itens de farmácia a alimentos. Depois, aos poucos, foi melhorando e abrindo outros tipos de comércio, como pensão e bares (E1). Para E2, quando da sua chegada, em 1967, havia o básico para sobrevivência, como citado: "O comércio aqui era muito fraquinho, porque, como era muito difícil de ir para fora, tinha o básico para sobrevivência". Em 2008, na chegada de E3, o comércio estava em pleno funcionamento, a produção de álcool e açúcar era predominante na cidade, fomentando a economia como um todo, como mencionado: "O comércio era melhor por causa da usina que estava funcionando a todo vapor, [...] depois deu uma queda da usina, aí diminuiu, muito comércio fechou".

Considerando o desenvolvimento do município, observa-se que as oportunidades de trabalho, inicialmente com as serrarias e a agricultura e, posteriormente, na agroindústria, foram responsáveis pelo crescimento de Naviraí e contribuíram para sua condição de polo urbano regional. Esse fato é visto por E2 como uma das causas do crescimento da cidade, sobretudo na agroindústria, como relatado: "É o emprego, né. Quando surgiu o frigorífico, aí teve bastante emprego e na redondeza pessoas falavam para família que Naviraí tinha empresa, que estava precisando disso e aquilo. Depois do frigorífico, aí veio a usina e continuou".

Aliados a isso, a localização do município e o acesso pelas rodovias contribuíram também para o desenvolvimento da cidade, como reitera E3: "Porque ela é o corredor, né, de acesso, tanto para o Sul como para o Norte". Ademais, E3 acredita que, mais recentemente, a instalação da Universidade Federal, da Universidade Estadual e de instituições privadas auxiliou no desenvolvimento da região.

De modo geral, constata-se que o desenvolvimento do município foi pautado no aproveitamento das potencialidades locais, principalmente a partir dos recursos naturais, como defendem diversos autores (AMARAL FILHO, 1996; ÁVILA, 2000; FERRO, 2003). Apesar disso, como a formação desse território ainda é recente, 66 anos desde a chegada dos pioneiros, e houve a apropriação do território por migrantes de várias regiões, discute-se ainda que não há uma forte identidade social totalmente constituída, nos termos de Ávila (2000) e Martins (2002), mas ainda em formação.

Com relação ao futuro, as entrevistadas (E1, E2 e E3) presumem que há possibilidade de um maior crescimento, dependendo da vontade política dos governos em nível local, estadual e federal. Neste sentido, insistem na necessidade de implantação de novas indústrias para gerar empregos e, consequentemente, fomentar a economia, como frisa E2: “É só ter emprego, tendo emprego a cidade cresce, a cidade expande, todo mundo tem dinheiro, o comércio vai bem, o comércio melhora".

Os dados descritos e analisados evidenciam que o município de Naviraí passou por momentos diversos em termos de apropriação do seu território e, principalmente, da sua territorialidade humana. As características fundamentais desse processo parecem estar centradas, em um primeiro momento, na importância que os pioneiros e migrantes estabeleceram na exploração econômica da terra e nas relações de poder que se firmaram na cidade e que se mantêm atualmente. Entretanto, é importante ressaltar que a visão dos entrevistados evidencia que o caminho do desenvolvimento pautado nas grandes indústrias, principalmente usinas e frigoríficos, coloca o município à mercê de um modelo de desenvolvimento que tem se mostrado 
frágil, uma vez que poucos empregadores respondem por uma parcela importante da oferta de empregos.

Sendo assim, discute-se a necessidade de criar condições de desenvolvimento a partir da conjugação de esforços locais com apoio externo, como salienta Cabugueira (2000). É muito importante que outras vias de desenvolvimento sejam construídas de forma endógena, com a participação de todos os atores sociais, devendo ser planejada, colaborativa e capaz de integrar os aspectos econômico, político, cultural e natural de forma mais equilibrada. Destaca-se o papel das diversas universidades do município, que podem, por meio de esforços conjuntos, instruir os atores no sentido de promover o desenvolvimento local.

\section{CONCLUSÕES}

Retomando o objetivo inicial de compreender como ocorreu a constituição e o desenvolvimento do município de Naviraí como polo urbano regional, sob o enfoque territorial, observa-se que diversos aspectos convergiram para isso, iniciando-se com a colonização, fomentada pelo governo federal, associada à existência de recursos naturais que eram abundantes, e, consequentemente, por meio do aproveitamento das potencialidades locais, como a vocação agrícola.

Com relação à análise E-P-C-N, pode-se notar que todos os aspectos foram relevantes para constituição do território. Quanto aos aspectos econômicos, enfatizam-se os ciclos econômicos, desde a madeira, o algodão e a agroindústria. Os aspectos políticos, por sua vez, podem ser vislumbrados por meio da atuação do governo federal que incentivou a colonização e do governo municipal no desenvolvimento do município. No contexto político, salienta-se ainda a importância da articulação política externa que os colonizadores mantinham, de modo especial na pessoa de Ariosto da Riva; e a articulação política interna, nos papéis desempenhados por Antônio Augusto dos Anjos.

Os aspectos culturais podem ser notados a partir da influência dos pioneiros e dos migrantes que vieram de várias regiões, especialmente de São Paulo e do Paraná, e da influência da cultura japonesa e do cooperativismo. Neste ponto, acentua-se, embora em menor grau, que a existência dos povos indígenas antes da colonização e a proximidade com as fronteiras do Paraguai influenciaram também nos costumes e nas tradições da região. Por fim, os aspectos da natureza podem ser vislumbrados como os mais relevantes para a constituição do município, devido aos aspectos naturais que foram explorados desde a chegada dos pioneiros.

Diante desse contexto, indica-se a utilização da análise E-P-C-N, proposta por Saquet (2009), para compreender a configuração de um território e como suporte para pensar o desenvolvimento local endógeno sustentado. Para isso, destaca-se que os atores locais precisam trabalhar de forma conjunta com agentes externos para melhorar as questões sociais, além do aspecto econômico, como apresentam Cabugueira (2000), Sachs (2004) e Pinto (2014). Neste contexto, as diversas universidades instaladas no município são apontadas como possíveis parceiras na busca pelo desenvolvimento local sustentado.

Além das questões expostas, vale ressaltar a importância da construção de uma identidade territorial dos atores locais. No caso estudado, observa-se que existem influências de migrantes de diversas regiões e a identidade dos atores ainda está em formação. Portanto, sugere-se, para futuras pesquisas, a investigação das identidades culturais do município. Um caminho interessante que oferece potencial é a compreensão do papel das cooperativas, sobretudo da 
COPASUL, uma das mais importantes do Estado, no desenvolvimento local e regional e de seu impacto no território.

\section{REFERÊNCIAS}

AMARAL FILHO, J. Desenvolvimento regional endógeno em um ambiente federalista. Planejamento e Políticas Públicas, Brasília, n. 14, p. 35-70, dez. 1996.

ARAÚJO, W. A.; TEMOTEO, J. A. G.; ANDRADE, M. O.; TREVIZAN, S. D. P. Desenvolvimento local, turismo e populações tradicionais: elementos conceituais e apontamentos para reflexão. Interações, Campo Grande, MS, v. 18, n. 4, p. 5-18, 2017.

ÁVILA, V. F. Realimentando discussão sobre teoria de Desenvolvimento Local (DL). Interações - Revista Internacional de Desenvolvimento Local, Campo Grande, MS, v. 8, n. 13, p. 133-40, 2006.

ÁVILA, V. F. Pressupostos para formação educacional em desenvolvimento local. Interações - Revista Internacional de Desenvolvimento Local, Campo Grande, MS, v. 1, n. 1, p. 63-76, set. 2000.

CABUGUEIRA, A. C. C. M. Do desenvolvimento regional ao desenvolvimento local: análise de alguns aspectos de política econômica regional. Gestão e Desenvolvimento, Campo Grande, MS, n. 9, p. 103-36, 2000.

COOPERATIVA AgRíCOLA SUL MATOGROSSENSE [COPASUL]. A cooperativa. COPASUL, Naviraí, [s.d.]. Disponível em: http://www.copasul.coop.br/institucional/a-cooperativa/1. Acesso em: 8 ago. 2019.

DEMATTEIS, G. Geografia democrática, território e desenvolvimento local. Formação, Presidente Prudente, v. 2, n. 12, p. 11-26, 2005.

EDUARDO, M. F.; SAQUET, M. A. A abordagem territorial como perspectiva teórico-conceitual: insights sobre a agroecologia no sudoeste paranaense. In: ENCONTRO NACIONAL DO GEÓGRAFOS, $16 ., 25$ a 31 jul. 2010, Porto Alegre. Anais [...]. Porto Alegre: ENG, 2010.

FARIAS, C. S. A influência da produção de mandioca na composição da identidade territorial do Vale do Juruá-AC. Revista Geonorte, Manaus, v. 7, n. 1 [edição especial], p. 604-22, 2013.

FERRO, R. F. F. C. Potencialidades de desenvolvimento local da comunidade de São Gabriel do Oeste em Termos de Ocupação. 2003. Dissertação (Mestrado em Desenvolvimento Local) - Universidade Católica Dom Bosco, Campo Grande, MS, Brasil, 2003.

GARCIA, D. C. Um lugar chamado Naviraí. Dourados, MS: Seriema, 2016.

GONÇALVES, D. L. A colonizadora Vera Cruz Mato Grosso e a formação de Naviraí. 134 f. 2015. Dissertação (Mestrado em História) - Universidade Federal da Grande Dourados (UFGD), Dourados, MS, 2015.

HASPER, N.; PEREIRA, C. M. S. (Org.). Projeto Jubileu de Ouro de Naviraí: as tecnologias e a rede social Facebook ajudam a comunidade escolar a resgatar a história do município. Naviraí, MS: NTE - Núcleo de Tecnologia Educacional, 2013.

INSTITUTO BRASILEIRO DE GEOGRAFIA E ESTATÍSTICA. Cidades. Naviraí. IBGE, Rio de Janeiro, [s.d.]. Disponível em: https://cidades.ibge.gov.br/brasil/ms/navirai/panorama. Acesso em: 18 jul. 2019.

INSTITUTO BRASILEIRO DE GEOGRAFIA E ESTATíSTICA. Cidades. Produto Interno Bruto dos Municípios. IBGE, Rio de Janeiro, [s.d.]. Disponível em: https://www.ibge.gov.br/estatisticas/economicas/contas- 
nacionais/9088-produto-interno-bruto-dos-municipios. html?t=pib-por-municipio\&c=5005707. Acesso em: 18 jul. 2019.

INSTITUTO BRASILEIRO DE GEOGRAFIA E ESTATÍ́STICA. Sistema IBGE de Recuperação Automática. Censo Demográfico 2010. IBGE, Rio de Janeiro, [s.d.]. Disponível em: https://sidra.ibge.gov.br/pesquisa/censodemografico/demografico-2010/inicial. Acesso em: 18 jul. 2019.

MARTINS, S. R. O. Desenvolvimento local: questões conceituais e metodológicas. Interações, Campo Grande, MS, v. 3, n. 5, p. 51-9, 2002.

MESSIAS, M. L. (Org.). Naviraí 50 anos construindo sonhos. Naviraí-MS: PSAF, 2013.

MICHEL, M. Metodologia e pesquisa científica em ciências sociais. São Paulo: Atlas, 2009.

MINAYO, M. C. S. (Org.). Pesquisa Social: teoria, método e criatividade. 3. ed. Petrópolis, RJ: Editora Vozes, 1994.

MORAES, J. L. A.; SCHNEIDER, S. Perspectiva territorial e abordagem dos sistemas produtivos localizados rurais: novas referências para o estudo do desenvolvimento rural. Revista Brasileira de Gestão e Desenvolvimento Regional, Taubaté, v. 6, n. 2, p. 287-320, 2010.

OLIVEIRA, E. Mato Grosso do Sul: venda da usina Coopernavi é concluída. Página Rural, 5 out. 2006. Disponível em: http://www.paginarural.com.br/noticia/49797/mato-grosso-do-sul-venda-da-usinacoopernavi-e-concluida. Acesso em: 8 ago. 2018.

PEREIRA, J. A.; CHAGAS, P. B.; BÁNKUTI, S. M. S. Perspectivas do território no sistema agroalimentar localizado: o caso da uva no município de Marialva-PR. Administração Pública e Gestão Social, v. 11, n. 2, p. 107-25, abr./jun., 2019.

PEREIRA, J. A.; RESCH, S.; DOCKHORN, M. S. M.; RODRIGUES, W. O. P.; SILVA, M. A. C. Desenvolvimento Local e Regional: características da Microrregião de Iguatemi do estado de Mato Grosso do Sul. Revista Eletrônica Científica do CRA-PR, Curitiba, v. 4, n. 2, p. 19-35, 2017.

PEREIRA, V. J.; PEREIRA, J. A. Território, Polo Industrial e Arranjo Produtivo Local: estudo no Polo Moveleiro do Município de Arapongas-PR. Perspectivas Contemporâneas, Campo Mourão, v. 13, n. 2, p. 24-43, 2018.

PINTO, A. C. B. Desenvolvimento local: a comunidade como coparticipante. Revista Brasileira de Planejamento e Desenvolvimento, Curitiba, v. 3, n. 1, p. 165-75, 2014.

PREFeItURA MUNICIPAL DE NAVIRAí [PMN]. Conheça Naviraí. Portal da Prefeitura Municipal, [s.d.]. Disponível em: https://www.navirai.ms.gov.br/. Acesso em: 19 jul. 2019.

PROGRAMA DAS NAÇÕES UNIDAS PARA O DESENVOLVIMENTO [PNUD]. Atlas do Desenvolvimento Humano do Brasil. PNUD, Brasília-DF, 2013. Disponível em: http://www.br.undp.org/content/brazil/pt/home/library/ idh/metodologia.html. Acesso em: 10 mar. 2017.

RAFFESTIN, C. Por uma geografia do poder. São Paulo: Ática, 1993.

RICHARDSON, R. J. Pesquisa social. 3. ed. São Paulo: Atlas, 2008.

SACHS, I. Desenvolvimento includente, sustentável, sustentado. Rio de Janeiro: Garamond, 2004.

SACK, Robert. Human territoriality: its theory and history. Cambridge: Cambridge University Press, 1986. 
SANTOS, L. M.; PEREIRA, A. M.; PAULA, A. M. N. R. Comunidades remanescentes de quilombos: reflexão sobre territorialidades. Revista Cerrados, v. 16, n. 1, p. 248-65, 2018.

SAQUET, M. A. A relação espaço-tempo e a apreensão do movimento em estudos territoriais. In: ENCONTRO DE GEÓGRAFOS DA AMÉRICA LATINA, 10., 20 a 26 mar. 2005, São Paulo. Anais [...]. São Paulo: Universidade de São Paulo, 2005.

SAQUET, M. A. Por uma abordagem territorial. In: SAQUET, M. A.; SPOSITO, E. S. (Org.). Territórios e territorialidades: teorias, processos e conflitos. São Paulo: Expressão Popular, 2009.

SAQUET, M. A. Abordagens e concepções de território. São Paulo: Outras Expressões, 2015.

SECRETARIA DE ESTADO DE MEIO AMBIENTE E DESENVOLVIMENTO ECONÔMICO. Estudo da dimensão territorial do estado de Mato Grosso do Sul: regiões de planejamento. Campo Grande: SEMADE, 2015.

SPOSITO, E. S.; JURADO DA SILVA, P. F. Cidades pequenas: perspectivas teóricas e transformações socioespaciais. Jundiaí: Paco Editorial, 2013.

TRIVIÑOS, A. N. S. Introdução à pesquisa em ciências sociais: a pesquisa qualitativa em educação. Atlas: São Paulo, 2010.

VALE, A. L. F.; SAQUET, M. A.; SANTOS, R. O território: diferentes abordagens e conceito-chave para a compreensão da migração. Faz Ciência-Sociedade, Espaço e Economia, v. 7, n. 1, p. 11-26, 2005.

ZANON, B. Local Development in Fragile Areas: re-territorialization processes in an alpine community. International Planning Studies, v. 19, n. 3-4, p. 335-58, 2014.

ZANON, B. Territorial Innovation in the Alps. Heterodox Reterritorialization Processes in Trentino, Italy. Italian Journal of Planning Practice, v. 8, n. 1, p. 1-37, 2018.

\section{Sobre os autores:}

Jaiane Aparecida Pereira: Doutora em Administração pela Universidade Estadual de Maringá (UEM). Professora adjunta da Universidade Federal de Mato Grosso do Sul (UFMS) - Campus de Naviraí. E-mail: jaiane.pereira@ufms.br, Orcid: http://orcid.org/0000-0003-4254-6311

Gabrielle Corrêa Zacarias: Graduada em Administração pela Universidade Federal de Mato Grosso do Sul (UFMS) - Campus de Naviraí. Administradora. E-mail: gabriellezcorrea@gmail.com, Orcid: http://orcid.org/0000-0002-3259-9260

Marco Antônio Costa da Silva: Doutor em Administração pela Universidade Nove de Julho (UNINOVE). Professor adjunto da Universidade Federal de Mato Grosso do Sul (UFMS) - Campus de Naviraí. E-mail: marco.silva@ufms.br, Orcid: http://orcid.org/0000-0003-3766-4292 
